\title{
Fish species richness is associated with the availability of landscape components across seasons in Amazonian floodplain
}

Carlos Edwar Carvalho Freitas ${ }^{\text {Corresp., }}{ }^{1}$, Laurie Laurenson ${ }^{2}$, Kedma Cristine Yamamoto ${ }^{1}$, Bruce Rider Forsberg , Miguel Petrere $\mathrm{Jr}^{4}$, Caroline Arantes ${ }^{5}$, Flavia Kelly Siqueira-Souza ${ }^{1}$

${ }^{1}$ Department of Fisheries Sciences / Faculty of Agriculture Sciences, Federal University of Amazonas, Manaus, Amazonas, Brazil

2 School of Life \& Environmental Sciences / Faculty of Science, Engineering \& Built Environment, Deakin University, Australia

3 Coordenação de Dinâmica Ambiental, Instituto Nacional de Pesquisas da Amazonia, Manaus, Amazonas, Brazil

4 Institute of Biological Sciences, Federal University of Pará, Belém, Pará, Brazil

${ }^{5}$ Center for Global Change and Earth Observations, University of Michigan - Ann Arbor, United States

Corresponding Author: Carlos Edwar Carvalho Freitas

Email address: cefreitas@ufam.edu.br

Understanding environmental biodiversity drivers in freshwater systems continues to be a fundamental challenge in studies of their fish assemblages. The present study seeks to determine the degree to which landscape variables of Amazonian floodplain lakes influences fish assemblages in these environments. Fish species richness was estimated in 15 Amazonian floodplain lakes during the high and low-water phases and correlated with the areas of four inundated wetland classes: (i) open water, (ii) flooded herbaceous, (iii) flooded shrubs and (iv) flooded forest estimated in different radius circular areas around each sampling site. Data were analyzed using generalized linear models with fish species richness, total and guilds as the dependent variable and estimates of buffered landscape areas as explanatory variables.Our analysis identified the significance of landscape variables in determining the diversity of fish assemblages in Amazonian floodplain lakes. Spatial scale was also identified as a significant determinant of fish diversity as landscape effects were more evident at larger spatial scales. In particular, (1) total species richness was more sensitive to variations in the landscape areas than number of species within guilds and (2) the spatial extent of the wetland class of shrubs was consistently the more influential on fish species diversity. 
1 Fish species richness is associated with the availability of landscape components across

2 seasons in Amazonian floodplain

3 Carlos Edwar de Carvalho Freitas ${ }^{a,{ }^{*}}$, Laurie Laurenson ${ }^{\mathrm{b}}$, Kedma Cristine Yamamoto ${ }^{a}$, Bruce

4 Rider Forsberg ${ }^{\mathrm{c}}$, Miguel Petrere Jrd ${ }^{\mathrm{d}}$, Caroline Arantes ${ }^{\mathrm{e}}$ and Flavia Kelly Siqueira-Souza ${ }^{\mathrm{a}}$

5 a Departamento de Ciências Pesqueiras, Universidade Federal do Amazonas. Manaus,

6 Amazonas, Brazil.

7 b School of Life and Environmental Sciences, Faculty of Science Engineering \& Built

8 Environment, Warrnambool Campus, Deakin University Australia. Australia.

9 c Coordenação de Dinâmica Ambiental. Instituto Nacional de Pesquisas da Amazonia.

10 Manaus, Amazonas, Brazil.

11 d PPG - ECOMAR - Programa de Pós-Graduação em Sustentabilidade de Ecossistemas

12 Costeiros e Marinhos, Universidade Santa Cecília. Santos, São Paulo, Brazil and.

13 PPGPUR - Programa de Pós-graduação em Planejamento e Uso de Recursos Renováveis,

14 UFSCar - Universidade Federal de São Carlos. Sorocaba, São Paulo, Brazil

15 e Department of Wildlife and Fisheries Sciences, Texas A\&M University, College Station. Texas, 16 USA.

17 * (Corresponding Author): Departamento de Ciências Pesqueiras. Universidade Federal do 18 Amazonas.

19 e-mail: cefreitas@ufam.edu.br

20 phone: 5592984146088

21

22

23

24

25

26

ABSTRACT 
27 Understanding environmental biodiversity drivers in freshwater systems continues to be a

28 fundamental challenge in studies of their fish assemblages. The present study seeks to

29 determine the degree to which landscape variables of Amazonian floodplain lakes influences

30 fish assemblages in these environments. Fish species richness was estimated in 15 Amazonian

31 floodplain lakes during the high and low-water phases and correlated with the areas of four

32 inundated wetland classes: (i) open water, (ii) flooded herbaceous, (iii) flooded shrubs and (iv)

33 flooded forest estimated in different radius circular areas around each sampling site. Data were

34 analyzed using generalized linear models with fish species richness, total and guilds as the

35 dependent variable and estimates of buffered landscape areas as explanatory variables. Our

36 analysis identified the significance of landscape variables in determining the diversity of fish

37 assemblages in Amazonian floodplain lakes. Spatial scale was also identified as a significant

38 determinant of fish diversity as landscape effects were more evident at larger spatial scales. In

39 particular, (1) total species richness was more sensitive to variations in the landscape areas

40 than number of species within guilds and (2) the spatial extent of the wetland class of shrubs

41 was consistently the more influential on fish species diversity.

\section{INTRODUCTION}


Floodplains are key environments for the health of large river ecosystems (Junk et al.,

54 2014), as they regulate water flow and nutrients that are essential for the life cycle of many

55 species (Junk, Bayley \& Sparks, 1989; Fernandes, 1997). Floodplains of the Amazon River are

56 highly productive, with estimations of total net primary productivity reaching $300 \mathrm{Tg} \mathrm{C}$ year-1 in

57 an area of $1.77 \times 10^{6} \mathrm{~km}^{2}$ (Melack et al., 2009). The high productivity of the Amazonian

58 floodplain is driven in part by seasonal changes in water level that can exceed $15 \mathrm{~m}$ and lead to

59 remarkable spatio-temporal changes in the landscape (i.e, flood pulse, Junk, Bayley \& Sparks,

60 1989). This high spatio-temporal heterogeneity of habitats across the landscape, including open

61 water, macrophyte meadows, flooded shrubs, forests and herbaceous regions, and large

62 extensions of ecotones integrated by a complex chain of connections, influence fishes

63 movement, feeding and reproductive behaviors as well as their growth and survival rates (Petry,

64 Bayley \& Markle, 2003; Siqueira-Souza \& Freitas 2004; Freitas et al., 2010a; Siqueira-Souza et 65 al., 2016).

While influences of local habitat features in these ecosystems on fishes have been relatively well studied (e.g. structural or physic-chemical variables measured within lakes) (e.g., Rodrigues \& Lewis, 1997; Tejerina-Garro, Réjean \& Rodriguez, 1998; Miranda, 2011; Freitas et al., 2014.), influences of landscape features have been generally overlooked. The few studies evaluating this issue have found landscape components, such as habitat heterogeneity (e.g., number or size of habitats) and land cover types (e.g., forest cover) influence both fish diversity

72 and fish biomass (Yager, Layman \& Allgeier, 2011; Siqueira-Souza et al., 2016; Lobón-Cervia et 73 al., 2015; Arantes et al., 2017; Castello et al., 2017). Given the magnitude of the Amazonian

74 floodplain, its variety of habitats (Siqueira-Souza et al., 2016; Freitas et al., 2010b; Hurd et al., 75 2016) and increasingly anthropogenic-driven impacts on its landscapes, a continuing 76 understanding of this issue is critically needed. Particularly, there is a need to understand how 77 fish diversity is influenced by the flood-pulse driven availability of habitat within the landscape. 
Herein, we tested the hypothesis that landscape components, represented by the spatial extent of four landscape variables (open water, flooded herbaceous, flooded shrub and flooded forest), significantly influenced fish diversity in Amazonian floodplain lakes, with the importance of each landscape variable being dependent on the hydrological period (i.e, high- and lowwater). Specifically, we evaluated how taxonomic and functional species richness, measured in high- and low-water periods, responded to the availability of landscape features that surrounded the sampled lakes. This evaluation provided an understanding of the regional species pool and usefulness for the long-term conservation of Amazonian floodplains (Freitas et al., 2014).

\section{MATERIAL AND METHODS}

\section{Study Area}

Fish assemblages were sampled in 15 lakes on the central Amazon floodplain along the

middle and lower Solimões River, 11 located on the margins of the main channel and four within geologically recent system (Hoorn et al, 2010) and is geomorphologically monotonous in its physical structure (Latrubesse \& Franzinelli, 2002). The associated floodplain is an active alluvial system still at work, blanketing and reworking the floodplain deposits (Latrubesse \&

97 Franzinelli, 2002). All 15 sampled lakes are located within this floodplain and are in general shallow lakes formed behind scroll bars by the overbank deposition of fine material.

The spatial extent of landscape features is substantially different between high and lowwater periods (Figs. 1, 2). The central Amazon floodplain is a dynamic sedimentary formation

101 that includes both marginal plains and isolated islands that are continuously re-worked by fluvial 102 erosion and sedimentation (Dunne et al., 1998). The geomorphological processes result in 103 variations in elevation and inundation, which have a fundamental effect on the distribution and 
104 dynamics of the floodplain vegetation and habitats (Junk, Bayley \& Sparks, 1989; Schöngart, et

105 al., 2002). As the elevation declines and inundation period increases, floodplain vegetation and

106 habitats change from alluvial forest to shrubs, herbaceous vegetation and finally, to open water.

107 These habitats are only available to fish when flooded and the extent of flooded habitats may

108 vary by a few orders of magnitude as the Amazon main channel undergoes its annual 10-12 m

109 flood cycle (Hess et al., 2003).

110

\section{Landscape component estimates}

$112 \quad$ Hess et al. (2003; 2015) published a dual-season (high and low-water) wetland

113 classification for the central Amazonian region, derived from $100 \mathrm{~m}$ L-band synthetic aperture

114 radar imagery. Nine landscape classes were identified for high and low-water conditions. Four

115 landscape variables defined by Hess et al. (2003) were used in our analytical models: Open

116 Water - also called non-vegetated flooded, represents aquatic habitats without vegetation cover

117 and includes lakes and secondary channels; Flooded Herbaceous - vegetation dominated by

118 non-woody plants, with $<25 \%$ trees or shrubs, the herbaceous cover is usually $\geq 25 \%$ but may

119 be less if it exceeds that of other vegetation; Flooded Shrubs - vegetation dominated by low

120 stature (height $0.5-5 \mathrm{~m}$ ) woody plants, with individuals or clumps not touching or interlocking,

121 shrub cover is usually $\geq 25 \%$ but may be less if it exceeds that of other vegetation; and, Flooded

122 Forest - closed canopy forest dominated by woody plants $>5 \mathrm{~m}$ in height, with interlocking

123 crowns, generally forming $60-100 \%$ of crown cover. The thematic wetland maps for high and

124 low-water periods were downloaded from NASA's Oak Ridge National Laboratory Distributed

125 Active Archive Center (https://daac.ornl.gov/cgi-bin/dsviewer.pl?ds id=1284) and imported into

126 ArcMap 10.1, together with fish sampling points digitized from GPS coordinates. Using the

127 Spatial Analyst - Extract by Circle Tool, we quantified the areas of landscape variables $\left(\mathrm{m}^{2}\right)$ in

$128500,1,000$ and 5,000 m (radius) circular buffers around each fish sampling site during low and 
129 high-water periods (Figs. 1,2). The buffer radii were chosen to allow the characterization of

130 landscape features at different spatial scales: (1) 500 m radius represents the area immediately

131 surrounding the sampling sites, it remains completely inundated for most of the year; (ii) 1,000

$132 \mathrm{~m}$ radius represents the area surrounding the sampling sites and includes some areas

133 inundated during the flood season; and, (iii) 5,000 $\mathrm{m}$ represents the area surrounding the

134 sampling sites plus areas that are inundated only during the high-water season and includes

135 secondary channels, other lakes and the main river channel. Further, we adapted the approach

136 employed by Lobón-Cerviá et al. (2015) who defined buffers based on the swimming ability of a

137 hypothetic fish with pre-defined body size and swimming speed. Our analyses considered that

138 fishes have diverse swimming and dispersal abilities. Thus, the definition of the buffers seeks to

139 delimit areas that are potentially explored by these fishes according to their different ecological

140 strategies, including their different migratory behaviors.

141

\section{Fish samplings}

143 Fish assemblages were sampled using 11 standardized floating gillnets $15 \mathrm{~m}$ long and 2

$144 \mathrm{~m}$ high with varying stretched mesh sizes $(30,40,50,60,70,80,90,100,110,120$ and 130

$145 \mathrm{~mm})$. Gillnets were deployed across all representative habitats in each lake system. Although

146 floating gillnets show selectivity towards pelagic and benthopelagic species, they are easier to

147 standardize than other fishing gear and were thus chosen. Furthermore, we note that the várzea

148 lakes are shallow which allows the nets to normally fish across the majority or all of the water

149 column (depending on the site). Nets were set at 06:00 am and remained in the water for 12

150 hours in Ananá, Araça, Baixio, lauara, Maracá, Poraqué, and Preto lakes; and for 48 hours in

151 Cacauzinho, Calado, Camaleão, Camboa, Central, Padre, Santo Antonio and Sacambu lakes.

152 The differences in the duration of fishing times resulted from the inclusion of data from multiple

153 independent research projects. However, sampling effort can be standardized and in the

154 present study it was defined as the product of the number of samplings and sampling time 
155 (hours; S1) and the efficacy of the fish assemblages sampling was evaluated using rarefaction

156 curves (S4). Gillnets were inspected every 6 hours to minimize predation on captured fishes.

157 Sampled fishes were euthanized by thermal shock and were usually identified in the field.

158 Unidentified specimens were fixed in $10 \%$ formalin and identified later in the laboratory. While

159 sampling frequency varied among lakes, each lake was sampled at least once during both high

160 and low-water periods (S1). Fish samplings were done under licenses 30052-1, 50662-1

161 (Instituto Chico Mendes de Conservação da Biodiversidade - ICMBio / Brazil).

162

163 Data Analysis

164 Generalized Linear Models (GLM) based on a Poisson distribution of probability were

165 used to evaluate relationships between fish assemblages and landscape area for each buffer for

166 high and low-water periods. We first modeled total species richness as response variables and

167 the areas of Open Water, Flooded Herbaceous, Flooded Shrub and Flooded Forest as

168 explanatory variables. Then, we classified species according to their trophic guilds, and

169 modeled the richness of carnivorous, omnivorous, and herbivorous species as response

170 variables, and landscape areas for each buffer as independent variables. Also, we classified

171 species according to their migratory behavior and modeled the richness of migrant and resident

172 species as response variables and the same pool of landscape areas as independent variables.

173 And finally, we classified species by the preferential position at the water column as pelagic and

174 benthopelagic to run similar analytical models. Because the number of fish sampled can be

175 correlated with species richness (Angermeier \& Schlosser, 1989), we included in the model fish

176 abundance as an independent variable. Models fitted to the low-water data were constrained to

177 the 5,000 $\mathrm{m}$ buffer as Flooded Shrubs were absent in both, 500 and 1,000 $\mathrm{m}$ buffers. Scatter-

178 plots with trend-lines were presented for variables with statistically significant relations.

179 Landscape spatial scales (i.e, different buffer sizes and associate landscape attributes) were 
180

181

182

183

184

185

186

187

188

189

190

191

192

193

194

195

196

198

199

200

201

202

203

204

205

compared at high and low-water using the explained deviance (pseudo- $R^{2}$ ), which was also used to assess model fit.

To minimize the effects of auto-correlation between landscape variables (Dormann et al., 2013), an aggregate variance inflation factor (vif) smaller than 2 was used as a criterion for deciding whether particular variables were included in the models. The Flooded Forest variable showed strong collinearity in most models and was only included in the high-water model for the $5,000 \mathrm{~m}$ buffer (S2). As collinearity between environmental variables was not constant in space, we also used Moran's I statistic (Fortin, Drapeau \& Legendere, 1989) to test for spatial autocorrelation in model residuals. Models for richness of carnivorous and omnivores species as function of the landscape variables in the $1,000 \mathrm{~m}$ buffer showed significative spatial autocorrelation; therefore, were not presented (S2).

Model fits were assessed by visual inspections of the residuals and only those that did not violate the assumptions of the generalized linear models were considered. The Bonferroni correction was employed to adjust for the effect of multiple statistical tests performed on the significance of explanatory variables (Shaffer, 1991).

All statistical analyses were conducted using R Statistical Software (R Core Team, 2013). General linear models (GLM) were fitted using the MASS Package (Ripley et al., 2013). Variance inflation factors (vif) were estimated using the CAR Package (Fox \& Weisberg, 2011) and Moran's I estimates were calculated using the APE Package (Paradis, Claude \& Strimmer, 2004).

\section{RESULTS}

A total of 178 species was collected. Characiformes was the most diverse group with 73 species, followed by Siluriformes with 64 species. Thirty-two and 52 species were present in more than 75 and $50 \%$ of lakes, respectively (S3). Species richness varied between 52 in Santo Antonio Lake and 89 in Maracá Lake. Species richness was consistently higher during low than 
206 in high-water periods. Trophic guilds richness was generally constant among lakes in high and

207 low-water seasons, but the number of resident species was generally higher than the number of 208 migrant species in all lakes (Table 1).

209 During the high-water season, flooded shrub area was the only significant landscape

210 variable (Table 2). Total species richness tended to be greater where shrub cover was greater

211 in different buffer scales (500 $\mathrm{m}$ and 1,000 m) (Table 2, Fig. 3a and 3b). This pattern also was

212 observed for resident species (Table 2, Fig. 3c and 3d). Omnivorous species richness was,

213 again, positively related with shrub cover but just in the small-scale (buffer of $500 \mathrm{~m}$ ) (Table 2,

214 Fig. 3e).

215 During the low-water season, flooded herbaceous had the strongest relationship with

216 fish diversity (Table 2). Flooded herbaceous was positively related to total species richness for

217 the larger $(5,000 \mathrm{~m})$ and medium $(1,000 \mathrm{~m})$ buffers (Table 2, Fig. 4a and 4b). A second

218 influential landscape variable was open water that positively affected total species richness and

219 resident species richness (Table 2, Fig. 4c and 4d). The number of fish sampled positively

220 influenced total species richness at the largest buffer, and showed a slightly positive, but not

221 statistically significant, relation with carnivorous richness $(p<0.10)$ (Table 2, Fig. 4e).

222 The best models with respect to the scale of analysis varied depending on the season

223 and fish group analyzed. During high-water, the small and medium sized buffers (500 m and

$2241,000 \mathrm{~m}$ buffers, respectively) explained more variability in the relationship between total

225 species richness and landscape variables (pseudo- $R^{2}>0.4$, Table 2). During this season,

226 models with omnivorous and herbivorous species richness as response variables, showed

227 better fits for the small $\left(500 \mathrm{~m}\right.$ ) buffer (pseudo- $\left.\mathrm{R}^{2}>0.45\right)$ than larger buffer sizes, although the

228 results for herbivores was not significant at any scale. Models for carnivorous and migrant

229 species richness during high-water showed weak relationships with the landscape variables at

230 all scales of analysis (pseudo- $R^{2}<0.40$, Table 2 ). 
231 During low-water, best fits were observed for the 500 and 1,000 m buffers (Table 2).

232 During this season, the best-fitted model was observed for the medium buffer when using

233 resident species as the response variable $\left(1,000 \mathrm{~m}\right.$ buffer, pseudo- $\left.\mathrm{R}^{2}=0.66\right)$.

234

235 DISCUSSION

236 Our results demonstrated that fish assemblages in the Amazon basin respond to

237 changes in the spatial extent of landscape components and that these responses vary

238 depending on the ecological strategies of the fish and on the stage of the hydrological cycle. It is

239 evident that fish species richness is related to the extent of shrub vegetation found in

240 surrounding floodplain lakes during high-water, and to the extent of herbaceous and open water

241 regions during low-water periods. Within this framework though, omnivorous and resident

242 species, regardless of season, showed stronger correlations with these categories than

243 carnivorous and migratory species. The results support the view that degradation of Amazonian

244 floodplain landscapes can impact fish diversity (Lobón-Cervia et al., 2015), with certain groups

245 being more vulnerable than others (Arantes et al., 2017).

246 Furthermore, our results support the contention that seasonal variations in landscape

247 components impact different groups of fishes at different times, and thus drive cross-habitat

248 migration within floodplains driven by flood-pulses (Fernandes, 1997; Castello, 2008). The

249 observed rise in resident species (e.g. Osteoglossum bicirrhosum, Cichla monoculus) richness

250 with increasing shrub cover, could reflect the lateral migration of these species into these

251 flooded habitats. It is likely that the flooded shrubs represent suitable regions for reproduction,

252 feeding and/or refuge. An observation that is also true for omnivorous species richness (e.g.,

253 Triportheus spp). It is also possible that there is a direct association between the spatial extent

254 of shrub cover and the extent of flooding during the high-water periods, that is, the observed

255 extent of this habitat class is maintained by the annual flooding regime (Silva, Costa \& Melack,

256 2010; Hess et al., 2015). Should this be true, then we can hypothesize that the regional 
257 abundance of shrubs together with their structural complexity are responsible for seasonality in

258 fish diversity. Studies have demonstrated that during low-water, many fish species migrate from

259 flooded habitats to lakes and secondary channels (Fernandes, 1997). Our observation that

260 during this season species richness is related to the amount of open water, is consistent with

261 previous studies showing that fish seek out lakes with greater water volumes (e.g, deep lakes)

262 possibly to avoid the effects of extreme droughts (Arantes et al., 2013).

263 A strong positive correlation is often expected between sample number and species

264 richness (Angermeier \& Schlosser, 1989). However, in our results the number of individuals was

265 only related to species richness in the low-water model. It is possible that this result is derived

266 from high populational densities and consequently higher catch rates of our sampling gears

267 during these periods of water retraction.

268 Our results showing differential influences of landscape components on fish diversity

269 across scales are consistent with previous studies in the Amazon floodplain areas (Freitas et al.,

270 2014; Siqueira-Souza et al., 2016) and support the view that spatial scale of investigation on the

271 processes affecting biodiversity matters (Chase \& Leibold, 2002; Willis \& Whitaker, 2002;

272 Rahbek, 2004). The medium scale buffer (500 m) explained high variability in the relationships

273 between fish diversity and landscape components for both seasons (low and high-water) and,

274 therefore, may represent an appropriate scale of analysis. However, further understanding of

275 the scales of processes driving spatial fish diversity patterns could be achieved by exploring

276 other scales, including different buffer sizes along with a local catchment (i.e., lake system

277 sensu Arantes et al., 2017; Castello et al., 2017).

278 The large amount of variation that remained unexplained by the landscape variables in

279 our results is likely related to the high spatial-temporal heterogeneity and variability of these

280 floodplain habitats and associated local environmental variables (Freitas et al., 2014; Siqueira-

281 Souza et al., 2016; Junk, Bayley \& Sparks, 1989; Röpke et al., 2016; Hurd et al., 2016). The

282 large dimensions and heterogeneity of the Amazon floodplain coupled with strong temporal 
283 variations result in a complex ecosystem whose structure and dynamics are governed by 284 deterministic and stochastic mechanisms operating across a broad range of temporal and 285 spatial scales (Freitas et al., 2014; Hess et al., 2015). Yet a large set of variables including 286 several that we did not include in our models, have been found to influence populations and 287 assemblage dynamics in these floodplains (e.g., depth, transparency, dissolved oxygen, 288 connectivity, e.g., Rodrigues \& Lewis, 1997; Freitas et al., 2014; Kemenes \& Forsberg, 2014; 289 Siqueira-Souza et al., 2016; Hurd et al., 2016; Lobón-Cervia et al., 2015). Habitat variations 290 between high- and low-water may, therefore, represent only part of the variations affecting fish 291 community structure in this system. Including these variables along with landcover components 292 may reveal stronger spatial patterns of fish diversity across the hydrological cycle. Understanding the importance of landscape components in structuring freshwater fish 294 assemblages is a core question in biological conservation, especially in light of the increasing 295 loss of aquatic habitats and the threat it poses to freshwater fish diversity globally (Dudgeon et 296 al., 2006). Our results demonstrate that fish species richness is closely linked to habitat 297 composition at the landscape scale and suggest that increasing losses of aquatic habitats in the 298 Amazon due to deforestation and river impoundment (Kahn, Freitas \& Petrere-Jr, 2014; Lees et 299 al., 2016; Lobón-Cervia et al., 2015; Arantes et al., 2017; Castello et al., 2017; Forsberg et al., 3002017 ) could disrupt these complex relationships with unpredictable consequences on 301 Amazonian fish diversity.

302

\section{CONCLUSIONS}

304 We conclude that the total species richness was more sensitive to variations in the landscape 305 areas than number of species within guilds and the spatial extent of the wetland class of shrubs 306 was consistently the more influential on fish species diversity. In synthesis, our results highlight 307 the importance of the geospatial extent of landscape variables surrounding Amazonian lakes 308 systems in the maintenance of their fish diversity. 


\section{References}

311 Angermeier PL, Schlosser IJ. 1989. Species-area relationship for stream fishes. Ecology $31270: 1450-1462$.

313 Arantes CC, Winemiller K, Petrere-Jr. M, Castello L, Hess L, Freitas CEC. 2017.

314 Relationships between forest cover and fish diversity in the Amazon River. Journal of Applied

315 Ecology 55:386-395 DOI: 10.1111/1365-2664.12967.

316 Arantes CC, Castello L, Cetra M, Schiling A. 2013. Environmental influences on the

317 distribution of arapaima in Amazon floodplains. Environmental Biology of Fishes 96:1257-1267.

318 Castello L. 2008. Lateral migration of Arapaima gigas in floodplains of the Amazon. Ecology of

319 Freshwater Fish 17:38-46.

320 Castello L, Hess L, Thapa R, Arantes CC, McGrath DG, Reno V, Isaac V. 2017. Fishery

321 yields vary with land cover on the Amazon River floodplain. Fish and Fisheries. DOI:

$32210.1111 /$ faf.12261.

323 Chase JM, Leibold MA. 2002. Spatial scale dictates the productivity-biodiversity relationship.

324 Nature 416:427-430.

325 Dormann CF, Elith J, Bacher S, Buchmann C, Gudrun C, Gabriel C, Garcia-Marques JR, 326 Gruber B, Lafourcade B, Leitão PJ, Munkemuller T, McClean C, Osborne PE, Reineking B, 327 Schröder B, Skidmore AK, Zurell D, Lautenbach S. 2013. Collinearity: a review of methods to 328 deal with it and a simulation study evaluating their performance. Ecography 36:27-46.

329 Dudgeon D, Arthington AH, Gessner MO, Kawabata ZI, Knowler DJ, Leveque C, Naiman 330 RJ, Prieur-Richard AH, Soto D, Stiassny MLJ, Sullivan CA. 2006. Freshwater biodiversity: 331 importance, threats, status and conservation challenges. Biological Reviews 81:163-162.

332 Dunne T, Mertes LAK, Meade RH, Rickey JE, Forsberg BR. 1998. Exchange of sediment 333 between the channel and floodplain of the Amazon River, Brazil. Geological Society of 334 American Bulletin 110: 450-467. 
335 Fernandes CC. 1997. Lateral migrations of fishes in Amazon floodplains. Ecology of

336 Freshwater Fish 2:36-44.

337 Forsberg BR, Melack JM, Dunne T, Barthem RB, Goulding M, Paiva, RCD, Soribas MV,

338 Silva Jr. UL, Weisser S. 2017. The potential impact of new Andean dams on Amazon fluvial

339 ecosystems. PLOS ONE DOI: 10.1371/journal.pone.0182254.

340 Fortin MJ, Drapeau P, Legendre P. 1989. Spatial autocorrelation and sampling design in plant

341 ecology. Vegetatio 83:209-222.

342 Fox J, Weisberg S. 2011. An $\{R\}$ companion to applied regression. 2nd edn. Thousand Oaks

343 CA. http://socserv.socsci.mcmaster.ca/jfox/Books/Companion.

344 Freitas CEC, Siqueira-Souza FK, Florentino AC, Hurd LE. 2014. The importance of spatial

345 scales to analysis of fish diversity in Amazonian floodplain lakes and implications for

346 conservation. Ecology of Freshwater Fish 23:470-477.

347 Freitas CEC, Siqueira-Souza FK, Guimarães AR, Santos FA, Santos ILA. 2010a.

348 Interconnectedness during high-water maintains similarity in fish assemblages of island

349 floodplain lakes in the Amazonian Basin. Revista Brasileira de Zoologia 27:931-938.

350 Freitas CEC, Siqueira-Souza FK, Prado KLL, Yamamoto KC, Hurd LE. 2010b. Fish species

351 diversity in Amazonian floodplain lakes. In: Rojas N, Prieto R, eds. Amazon Basin: Plant Life,

352 Wildlife and Environment. Nova York: Science Publishers 41-76.

353 Furch, K. 1984. Water chemistry of the Amazon basin: The distribution of chemical elements

354 among freshwaters. In H. Sioli, (Ed.). The Amazon: Limnology and landscape ecology of a

355 mighty tropical river and its basin (pp.167-199). Berlim: Monographiae Biologicae, Springer.

356 Hess LL, Melack JM, Affonso AG, Barbosa C, Gastil-BuhI M, Novo MLM. 2015. Wetlands

357 of the Lowland Amazon Basin: Extent, Vegetative Cover, and Dual-season Inundated Area as

358 Mapped with JERS-1 Synthetic Aperture Radar. Wetlands 35:745-756. 
359 Hess LL, Melack JM, Novo EMLM, Barbosa CCF, Gastil M. 2003. Dual-season mapping of

360 wetland inundation and vegetation for the central Amazon basin. Remote Sensing of

361 Environment 84:404-428.

362 Hoorn C, Wesselingh FP, ter Steege H, Bermudez MA, Mora A, Sevink J, Sanmartin I,

363 Sanchez-Meseguer A, Anderson CL, Figueiredo JP, Jaramillo C, Riff D, Negri FR,

364 Hooghiemstra H, Lundberg J, Stadler T, Särkinen T, Antonelli A. 2010. Amazonia through

365 time: Andean uplift, climate change, landscape evolution, and biodiversity. Science 330:927-

366931.

367 Hurd LE, Souza RGS, Siqueira-Souza FK, Cooper GJ, Kahn JR, Freitas CEC. 2016.

368 Amazon floodplain fish communities: habitat connectivity and conservation in a rapidly

369 deteriorating environment. Biological Conservation 195:118-127.

370 Junk WJ, Bayley PB, Sparks RE. 1989. The flood pulse concept in river - floodplain systems.

371 In: Dodge DP, ed. Proceedings of the International Large River Symposium (LARS). Canadian

372 Special Publications of Fisheries and Aquatic Science 106:110-127.

373 Junk WJ, Piedade MT, Lourival R, Wittman F, Kandus P, Lacerda LD, Bozelli RL, Esteves

374 F, Nunes da Cunha C, Maltchik L, Schöngart J, Schaeffer-Novelli Y, Agostinho AA. 2014.

375 Brazilian wetlands: their definition, delineation, and classification for research, sustainable

376 management, and protection. Aquatic Conservation: Marine and Freshwater Ecosystems 24:5-

37722.

378 Kahn J, Freitas CEC, Petrere-Jr. M. 2014. False shades of green: the case of Brazilian

379 Amazonian hydropower. Energies 7:6063-6082.

380 Kemenes A, Forsberg BR. 2014. Factors influencing the structure and spatial distribution of

381 fishes in the headwater streams of the Jaú River in the Brazilian Amazon. Brazilian Journal of

382 Biology 74:23-32.

383 Latrubesse EM, Franzinelli E. 2002. The Holocene alluvial plain of the middle Amazon River,

384 Brazil. Geomorphology 44:241-257. 
385 Lees AC, Peres CA, Fearnside PM, Schneider M, Zuanon JAS. 2016. Hydropower and the 386 future of Amazonian biodiversity. Biodiversity and Conservation 25:451-466.

387 Lobón-Cervia J, Hess LH, Melack J, Araújo-Lima CARM. 2015. The importance of forest 388 cover for fish richness and abundance on the Amazon floodplain. Hydrobiologia 750:245-255.

389 Melack JM, Novo EMLM, Forsberg BR, Piedade MTF, Maurice L. 2009. Floodplain

390 ecosystem processes. In: Keller M, Bustamante MG, Dias PS, eds. Amazonia and Global

391 Change. Washington, American Geophysical Union: 525-541.

392 Miranda LE. 2011. Depth as an organizer of fish assemblages in floodplain lakes. Aquatic 393 Sciences 73:211-221.

394 Paradis E, Claude J, Strimmer K. 2004. APE: analysis of phylogenetics and evolution in R 395 language. Bioinformatics 20:289-290.

396 Petry P, Bayley PB, Markle DF. 2003. Relationships between fish assemblages, macrophytes 397 and environmental gradients in the Amazon River floodplain. Journal of Fish Biology 63:547398579.

399 R Core Team 2.15.3, 2013. R: A language and environment for statistical computing. Vienna: $R$ 400 Foundation for Statistical Computing. ISBN 3-900051-07-0, URL. http://www.R-project.org/. 401 June 3, 2013.

402 Rahbek C. 2004. The role of spatial scale and the perception of large-scale species-richness 403 patterns. Ecology Letters 8:224-239.

404 Ripley B, Venables B, Hornik K, Gebhardt A, Firth D. 2013. MASS - Modern Applied 405 Statistics with S. http://www.stats.ox.ac.uk/pub/MASS4.

406 Rodriguez MA, Lewis WM. 1997. Structure of fish assemblages along environmental 407 gradients in floodplain lakes of the Orinoco River. Ecological Monographs 67:109-128.

408 Röpke CP, Amadio SA, Winemiller KO, Zuanon JAS. 2016. Seasonal dynamics of the fish 409 assemblage in a floodplain lake at the confluence of the Negro and Amazon Rivers. Journal of 410 Fish Biology 89:194-212. 
411 Schöngart J, Piedade MTF, Ludwigshausen S, Horna V, Worbes M. 2002. Phenology and

412 stem growth periodicity of tree species in Amazonian floodplain forests. Journal of Tropical

413 Ecology 18:581-597.

414 Shaffer JP. 1991. Multiple hypothesis testing. Annual Review of Psychology 46:561-584.

415 Silva TSF, Costa MPF, Melack JM. 2010. Spatial and temporal variability of macrophyte cover

416 and productivity in the eastern Amazon floodplain: A remote sensing approach. Remote

417 Sensing of Environment 114:1998-2010.

418 Siqueira-Souza FK, Freitas CEC, Hurd LE, Peterere-Jr. M. 2016. Amazon floodplain fish

419 diversity at different scales: do time and place really matter? Hydrobiologia 776:99-110.

420 Siqueira-Souza FK, Freitas CEC. 2004. Fish diversity of floodplain lakes on the lower stretch

421 of the Solimões River. Brazilian Journal of Biolology 64:501-510.

422 Tejerina-Garro FL, Réjean F, Rodriguez MA. 1998. Fish community structure in relation to

423 environmental variation in floodplain lakes of the Araguaia River, Amazon Basin. Environmental

424 Biology of Fish 51:399-410.

425 Willis KJ, Whitaker RJ. 2002. Species diversity-scale matters. Science 295:1245-1248.

426 Yager LA, Layman CA, Allgeier JE. 2011. Effects of habitat heterogeneity at multiple scales

427 on fish community assembly. Oecologia 167:219-232. 


\section{Table $\mathbf{1}$ (on next page)}

Ecological measures for each lake and hydrological season.

Where HW = high-water, LW = low-water (LW), S - species richness, SC - carnivorous richness, SO - omnivorous richness, $\mathrm{SH}$ - herbivorous richness, $\mathrm{M}$ - migrant richness, $\mathrm{R}$ resident richness, $\mathrm{P}$ - pelagic richness and $\mathrm{B}$ - benthopelagic richness. 
1 Table 1. Ecological measures for each lake and by high-water (HW) and low-water (LW) seasons. S - species richness, SC -

2 carnivorous richness, $\mathrm{SO}$ - omnivorous richness, $\mathrm{SH}$ - herbivorous richness, $\mathrm{M}$ - migrant richness, $\mathrm{R}$ - resident richness, $\mathrm{P}$ -

3 pelagic richness and $\mathrm{B}-$ benthopelagic richness.

\begin{tabular}{|c|c|c|c|c|c|c|c|c|c|c|c|c|c|c|c|c|}
\hline \multirow[t]{2}{*}{ Lake } & \multicolumn{2}{|c|}{$\mathrm{S}$} & \multicolumn{2}{|c|}{ SC } & \multicolumn{2}{|c|}{ SO } & \multicolumn{2}{|c|}{$\mathrm{SH}$} & \multicolumn{2}{|c|}{$M$} & \multicolumn{2}{|c|}{$\mathrm{R}$} & \multicolumn{2}{|c|}{$P$} & \multicolumn{2}{|c|}{$B$} \\
\hline & $\mathrm{HW}$ & LW & $\mathrm{HW}$ & LW & HW & LW & HW & LW & $\mathrm{HW}$ & LW & HW & LW & HW & LW & HW & LW \\
\hline Ananá & 65 & 74 & 18 & 21 & 18 & 17 & 65 & 74 & 24 & 26 & 31 & 32 & 22 & 23 & 43 & 50 \\
\hline Araçá & 63 & 73 & 16 & 16 & 18 & 18 & 63 & 73 & 20 & 21 & 29 & 35 & 17 & 21 & 46 & 52 \\
\hline Baixio & 59 & 75 & 18 & 19 & 17 & 17 & 59 & 75 & 20 & 20 & 26 & 34 & 18 & 19 & 39 & 56 \\
\hline Cacauzinho & 60 & 62 & 14 & 14 & 16 & 17 & 60 & 62 & 20 & 21 & 23 & 26 & 17 & 18 & 43 & 44 \\
\hline Calado & 63 & 62 & 15 & 14 & 17 & 17 & 63 & 62 & 19 & 18 & 23 & 24 & 22 & 21 & 40 & 40 \\
\hline Camaleão & 79 & 57 & 21 & 20 & 19 & 18 & 79 & 57 & 23 & 20 & 32 & 27 & 23 & 20 & 55 & 36 \\
\hline Camboa & 66 & 72 & 18 & 18 & 16 & 16 & 66 & 72 & 23 & 24 & 31 & 34 & 23 & 25 & 43 & 47 \\
\hline Central & 57 & 65 & 11 & 13 & 14 & 15 & 57 & 65 & 23 & 23 & 25 & 28 & 22 & 22 & 35 & 43 \\
\hline lauara & 59 & 80 & 16 & 16 & 17 & 17 & 59 & 80 & 18 & 18 & 26 & 36 & 17 & 22 & 42 & 58 \\
\hline Maracá & 89 & 62 & 22 & 21 & 29 & 20 & 89 & 62 & 29 & 28 & 33 & 29 & 26 & 17 & 62 & 45 \\
\hline Padre & 54 & 82 & 12 & 12 & 11 & 12 & 54 & 82 & 23 & 22 & 25 & 34 & 14 & 27 & 40 & 55 \\
\hline Poraqué & 58 & 55 & 10 & 10 & 11 & 11 & 58 & 55 & 23 & 23 & 25 & 26 & 21 & 12 & 37 & 43 \\
\hline Preto & 62 & 55 & 13 & 13 & 19 & 18 & 62 & 55 & 23 & 21 & 22 & 17 & 16 & 15 & 46 & 40 \\
\hline
\end{tabular}




\begin{tabular}{|c|c|c|c|c|c|c|c|c|c|c|c|c|c|c|c|c|}
\hline Sacambú & 61 & 74 & 11 & 12 & 15 & 16 & 61 & 74 & 24 & 25 & 27 & 36 & 20 & 28 & 41 & 46 \\
\hline Santo Antonio & 52 & 69 & 14 & 14 & 11 & 12 & 52 & 69 & 29 & 20 & 25 & 33 & 22 & 24 & 30 & 43 \\
\hline
\end{tabular}

4 


\section{Table 2 (on next page)}

Summary of general linear models.

Species richness is the response variable and open water area (OW), flooded herbaceous area (FH), flooded shrubs area (FS), flooded forest area (FF) and number of sampled fish ( $n$ ) were explanatory variables.Model coefficients are exhibited when they are significant at least for $p \& \lambda \tau ; 0.10$. 
1 Table 2. Summary of general linear models using species richness as response variable and open water

2 area (OW), flooded herbaceous area (FH), flooded shrubs area (FS), flooded forest area (FF) and

3 number of sampled fish ( $n$ ) as explanatory variables. Model coefficients are exhibited when they are

4 significant at least for $p<0.10$.

\begin{tabular}{|c|c|c|c|c|c|c|c|}
\hline Model & df & OW & $\mathrm{FH}$ & FS & $\mathrm{FF}$ & $\mathrm{N}$ & Pseudo-R ${ }^{2}$ \\
\hline \multicolumn{8}{|c|}{ Total Species Richness } \\
\hline $500 \mathrm{~m} / \mathrm{high}$ water & 11 & Ns & Ns & $0.02^{*}$ & ex & Ns & 0.47 \\
\hline $500 \mathrm{~m} / \mathrm{low}$ water & 11 & Ns & $0.07 \#$ & $\mathrm{Ni}$ & Ns & Ns & 0.39 \\
\hline $1000 \mathrm{~m} / \mathrm{high}$ water & 11 & Ns & Ns & $0.01^{*}$ & ex & Ns & 0.47 \\
\hline $1000 \mathrm{~m} /$ low water & 12 & $0.001^{*}$ & $0.02^{*}$ & $\mathrm{Ni}$ & ex & Ns & 0.56 \\
\hline 5000 m / high water & 11 & Ns & Ns & Ns & ex & Ns & 0.37 \\
\hline $5000 \mathrm{~m} /$ low water & 11 & Ns & $0.003^{*}$ & Ns & ex & $0.001^{*}$ & 0.52 \\
\hline \multicolumn{8}{|l|}{ Carnivorous Richness } \\
\hline $500 \mathrm{~m} / \mathrm{high}$ water & 11 & Ns & Ns & Ns & ex & Ns & 0.35 \\
\hline 500 m / low water & 12 & Ns & Ns & $\mathrm{Ni}$ & $-0.018 \#$ & Ns & 0.46 \\
\hline 1000 m / high water & 11 & Ns & Ns & Ns & ex & Ns & 0.36 \\
\hline $1000 \mathrm{~m} / \mathrm{low}$ water & 12 & Ns & Ns & $\mathrm{Ni}$ & ex & Ns & 0.18 \\
\hline 5000 m / high water & 11 & Ns & Ns & Ns & ex & Ns & 0.42 \\
\hline $5000 \mathrm{~m} /$ low water & 11 & Ns & Ns & Ns & ex & Ns & 0.32 \\
\hline \multicolumn{8}{|l|}{ Omnivorous Richness } \\
\hline $500 \mathrm{~m} / \mathrm{high}$ water & 10 & Ns & Ns & $0.04^{*}$ & Ns & Ns & 0.46 \\
\hline $500 \mathrm{~m} / \mathrm{low}$ water & 11 & Ns & Ns & $\mathrm{Ni}$ & Ns & Ns & 0.20 \\
\hline 1000 m / high water & 11 & Ns & Ns & $0.01^{*}$ & ex & Ns & 0.48 \\
\hline $1000 \mathrm{~m} / \mathrm{low}$ water & 12 & Ns & Ns & $\mathrm{Ni}$ & ex & Ns & 0.12 \\
\hline 5000 m / high water & 11 & Ns & Ns & Ns & ex & Ns & 0.18 \\
\hline $5000 \mathrm{~m} /$ low water & 11 & Ns & Ns & $0.001 \#$ & ex & Ns & 0.34 \\
\hline \multicolumn{8}{|l|}{ Herbivorous Richness } \\
\hline $500 \mathrm{~m} / \mathrm{high}$ water & 11 & Ns & Ns & Ns & ex & Ns & 0.59 \\
\hline $500 \mathrm{~m} /$ low water & 11 & Ns & Ns & $\mathrm{Ni}$ & Ns & Ns & 0.07 \\
\hline $1000 \mathrm{~m} /$ high water & 11 & Ns & Ns & Ns & ex & Ns & 0.35 \\
\hline $1000 \mathrm{~m} / \mathrm{low}$ water & 12 & Ns & Ns & $\mathrm{Ni}$ & ex & Ns & 0.02 \\
\hline $5000 \mathrm{~m} /$ high water & 11 & Ns & Ns & Ns & ex & Ns & 0.34 \\
\hline $5000 \mathrm{~m} /$ low water & 11 & Ns & Ns & Ns & ex & Ns & 0.50 \\
\hline \multicolumn{8}{|l|}{ Migrant Richness } \\
\hline $500 \mathrm{~m} / \mathrm{high}$ water & 11 & Ns & Ns & Ns & ex & Ns & 0.33 \\
\hline
\end{tabular}




\begin{tabular}{|c|c|c|c|c|c|c|c|}
\hline $500 \mathrm{~m} / \mathrm{low}$ water & 11 & Ns & Ns & $\mathrm{Ni}$ & Ns & Ns & 0.15 \\
\hline $1000 \mathrm{~m} /$ high water & 11 & Ns & Ns & Ns & ex & Ns & 0.40 \\
\hline $1000 \mathrm{~m} / \mathrm{low}$ water & 12 & Ns & Ns & $\mathrm{Ni}$ & ex & Ns & 0.23 \\
\hline $5000 \mathrm{~m} / \mathrm{high}$ water & 11 & Ns & Ns & Ns & ex & Ns & 0.55 \\
\hline 5000 m / low water & 11 & Ns & Ns & Ns & ex & Ns & 0.22 \\
\hline \multicolumn{8}{|l|}{ Resident Richness } \\
\hline $500 \mathrm{~m} / \mathrm{high}$ water & 11 & Ns & Ns & $0.03^{*}$ & ex & Ns & 0.39 \\
\hline $500 \mathrm{~m} /$ low water & 12 & $0.04 \#$ & Ns & $\mathrm{Ni}$ & ex & Ns & 0.56 \\
\hline $1000 \mathrm{~m} / \mathrm{high}$ water & 11 & Ns & Ns & $0.01^{*}$ & ex & Ns & 0.34 \\
\hline $1000 \mathrm{~m} /$ low water & 12 & $0.01^{*}$ & Ns & $\mathrm{Ni}$ & ex & Ns & 0.66 \\
\hline $5000 \mathrm{~m} / \mathrm{high}$ water & 11 & Ns & Ns & Ns & ex & Ns & 0.19 \\
\hline $5000 \mathrm{~m} /$ low water & 11 & Ns & Ns & Ns & ex & Ns & 0.35 \\
\hline \multicolumn{8}{|l|}{ Pelagic Richness } \\
\hline $500 \mathrm{~m} /$ high water & 11 & Ns & Ns & Ns & ex & Ns & 0.53 \\
\hline $500 \mathrm{~m} /$ low water & 11 & Ns & Ns & $\mathrm{Ni}$ & Ns & Ns & 0.06 \\
\hline $1000 \mathrm{~m} /$ high water & 11 & Ns & Ns & Ns & ex & Ns & 0.47 \\
\hline $1000 \mathrm{~m} /$ low water & 12 & Ns & Ns & $\mathrm{Ni}$ & ex & Ns & 0.24 \\
\hline $5000 \mathrm{~m} / \mathrm{high}$ water & 10 & Ns & Ns & Ns & Ns & Ns & 0.18 \\
\hline $5000 \mathrm{~m} /$ low water & 11 & Ns & $0.001 \#$ & Ns & Ex & Ns & 0.33 \\
\hline \multicolumn{8}{|c|}{ Benthopelagic Richness } \\
\hline $500 \mathrm{~m} / \mathrm{high}$ water & 11 & Ns & Ns & $0.02 \#$ & ex & Ns & 0.45 \\
\hline $500 \mathrm{~m} /$ low water & 12 & Ns & $0.09 \#$ & $\mathrm{Ni}$ & ex & Ns & 0.47 \\
\hline $1000 \mathrm{~m} /$ low water & 12 & Ns & Ns & $\mathrm{Ni}$ & ex & Ns & 0.41 \\
\hline $5000 \mathrm{~m} /$ high water & 11 & Ns & Ns & Ns & ex & Ns & 0.39 \\
\hline $5000 \mathrm{~m} /$ low water & 11 & Ns & Ns & Ns & ex & Ns & 0.34 \\
\hline
\end{tabular}

5 Obs: $\mathrm{df}$ = residual degrees of freedom, ex: previously excluded by collinearity; Ni: not included in the

6 model, Ns: not significant; \#: $0.10<p<0.05$; * $0.05<p<0.01 ;{ }^{* *}: p<0.01$. 
Figure 1

Map of study area at the lower stretch of the Solimões River showing the lakes sampled during high water season and the buffers of 500, 1000 and $5000 \mathrm{~m}$.

At this season, the aquatic environments are expanded and the landscape is mostly aquatic and lakes, river and channels are connected.

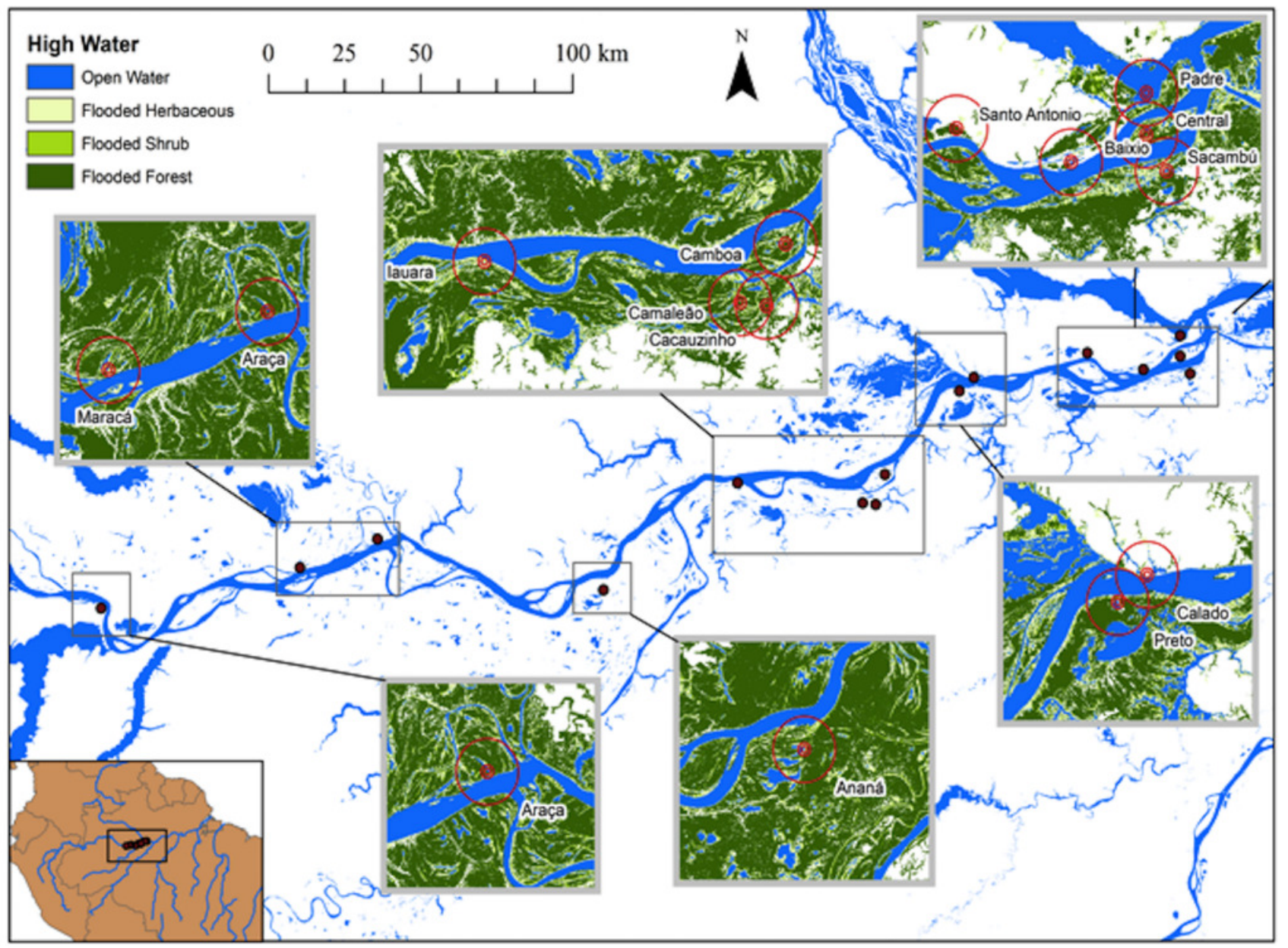


Figure 2

Map of the study area showing the lakes sampled during low water seasons and the buffers of 500,1000 and $5000 \mathrm{~m}$.

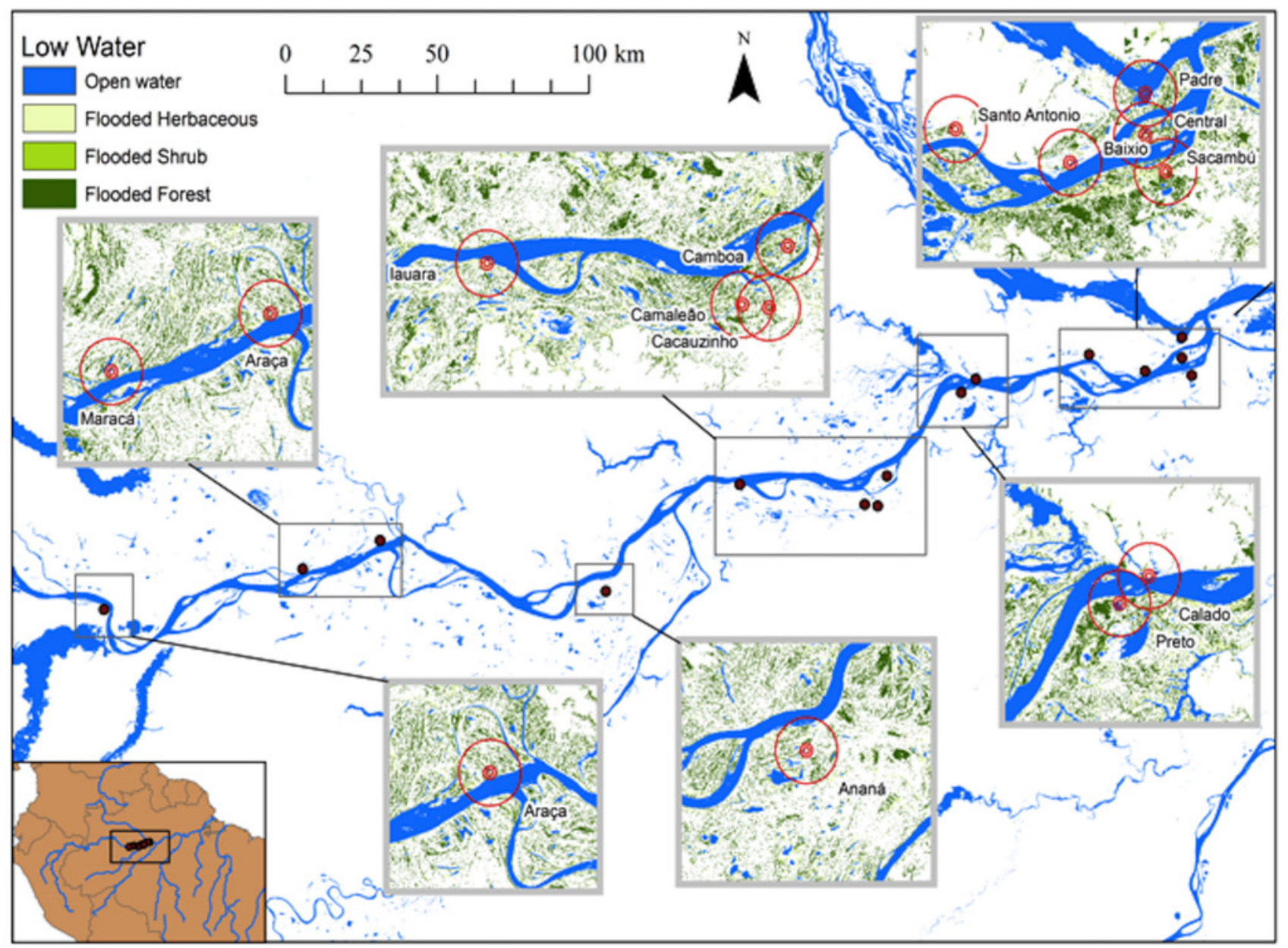




\section{Figure 3}

Scatter-plots by buffer and high-water season

$500 \mathrm{~m}$ - (a) total species richness vs. flooded shrub; (b) omnivorous richness vs. flooded shrub; (c) resident richness vs. flooded shrub; $1000 \mathrm{~m}$ - (d) Total sp vs. flooded and (e) resident richness vs. flooded shrub Tendency lines for the models with significative independent variables, where points are observed values of species richness per site, full lines are fitted lines and dotted lines are confidence intervals at 95\%. 

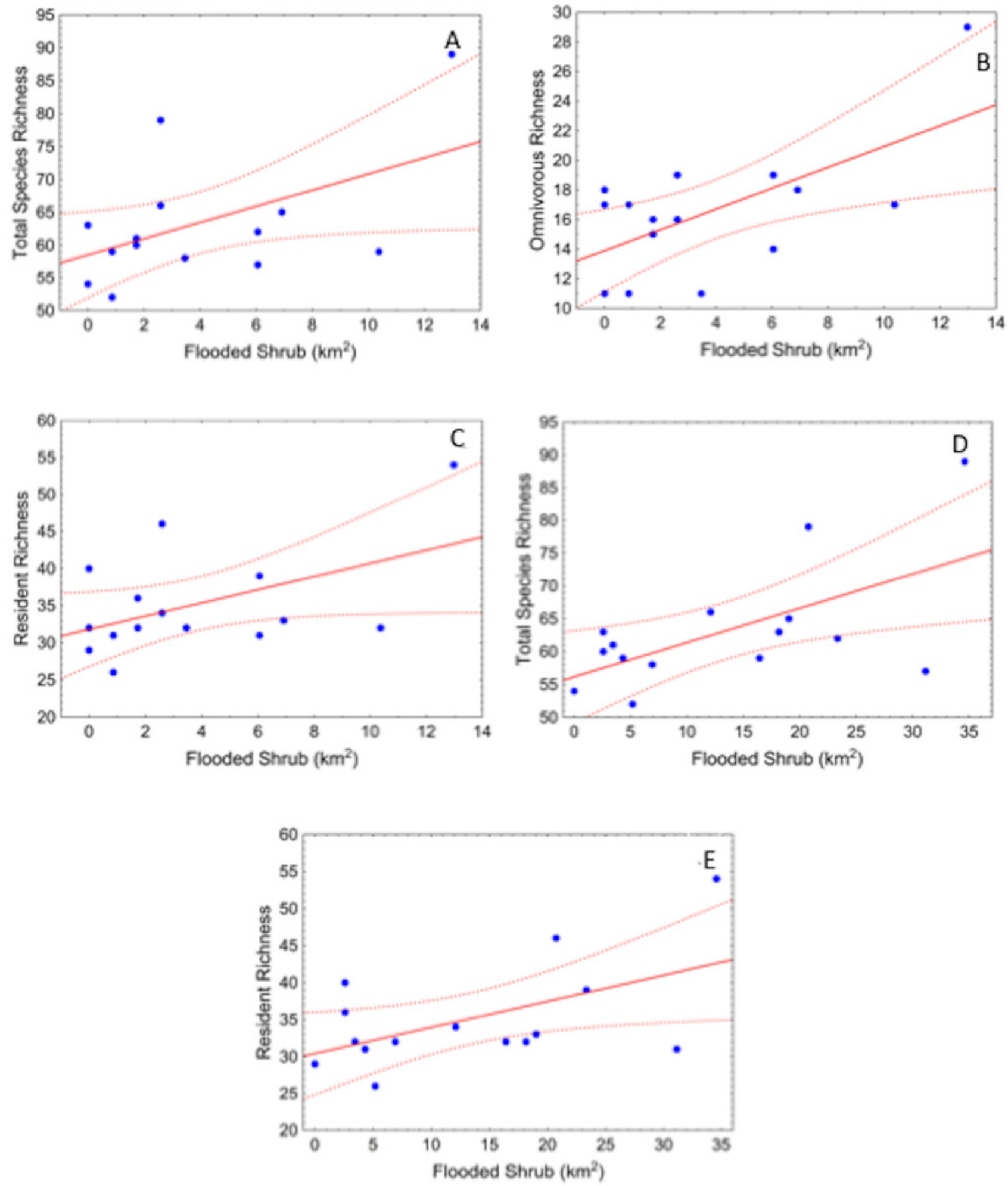


\section{Figure 4}

Scatter-plots by buffer during low-water season.

$1000 \mathrm{~m}$ - (a) total species richness vs. open water, (b) resident richness vs. open water, and (c) total species richness vs. flooded herbaceous; and, $5000 \mathrm{~m}$ - (e) total species richness vs. flooded herbaceous and ( $f$ ) total species richness vs. number of individuals. Tendency lines for the models with significative independent variables, where points are observed values of species richness per site, full lines are fitted lines and dotted lines are confidence intervals at $95 \%$. 

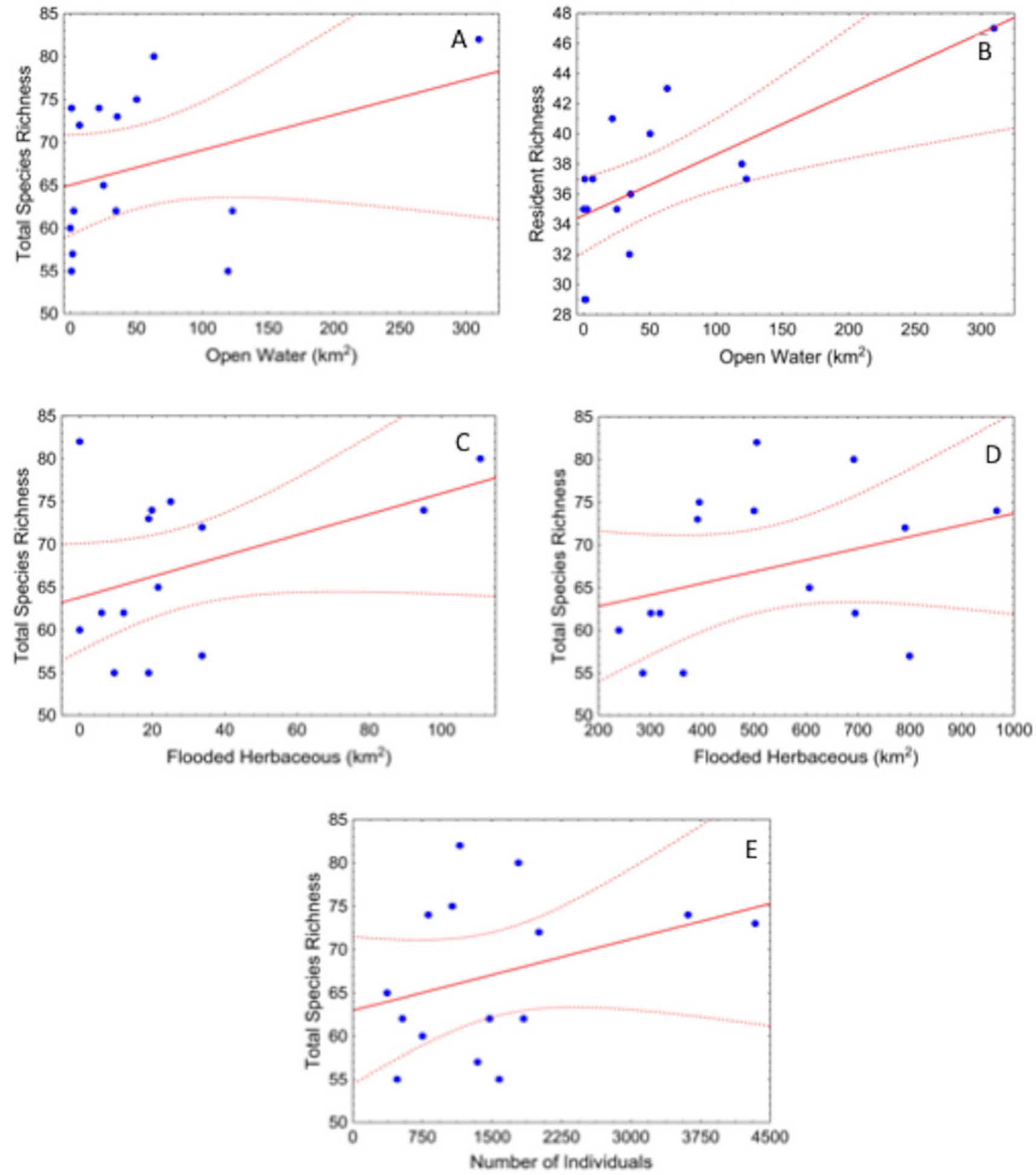